\title{
Plastic architecture of bacterial genome revealed by comparative genomics of Photorhabdus variants Sophie Gaudriault ${ }^{* \dagger}$, Sylvie Pages ${ }^{* \dagger}$, Anne Lanois ${ }^{* \dagger}$, Christine Laroui ${ }^{* \dagger}$, Corinne Teyssier ${ }^{\ddagger}$, Estelle Jumas-Bilak ${ }^{*}$ and Alain Givaudan ${ }^{*+}$
}

Addresses: *INRA, UMR 1133, Laboratoire EMIP, Place Eugène Bataillon, F-34095 Montpellier, France. 'Université Montpellier 2, UMR 1133, Laboratoire EMIP, Place Eugène Bataillon, F-34095 Montpellier, France. *Université Montpellier 1, EA 3755, Laboratoire de BactériologieVirologie, 15, Avenue Charles Flahault, BP 14491, F-3406o Montpellier Cedex 5, France.

Correspondence: Sophie Gaudriault. Email: sgaudriault@univ-montp2.fr

Published: 22 July 2008

Genome Biology 2008, 9:RII7 (doi:I0.I I86/gb-2008-9-7-r I I7)

The electronic version of this article is the complete one and can be found online at http://genomebiology.com/2008/9/7/RII7
Received: 15 April 2008

Revised: 12 June 2008

Accepted: 22 July 2008

(c) 2008 Gaudriault et al.; licensee BioMed Central Ltd.

This is an open access article distributed under the terms of the Creative Commons Attribution License (http://creativecommons.org/licenses/by/2.0), which permits unrestricted use, distribution, and reproduction in any medium, provided the original work is properly cited.

\begin{abstract}
Background: The phenotypic consequences of large genomic architecture modifications within a clonal bacterial population are rarely evaluated because of the difficulties associated with using molecular approaches in a mixed population. Bacterial variants frequently arise among Photorhabdus luminescens, a nematode-symbiotic and insect-pathogenic bacterium. We therefore studied genome plasticity within Photorhabdus variants.

Results: We used a combination of macrorestriction and DNA microarray experiments to perform a comparative genomic study of different $P$. luminescens TTOI variants. Prolonged culturing of TTOI strain and a genomic variant, collected from the laboratory-maintained symbiotic nematode, generated bacterial lineages composed of primary and secondary phenotypic variants and colonial variants. The primary phenotypic variants exhibit several characteristics that are absent from the secondary forms. We identify substantial plasticity of the genome architecture of some variants, mediated mainly by deletions in the 'flexible' gene pool of the TTOI reference genome and also by genomic amplification. We show that the primary or secondary phenotypic variant status is independent from global genomic architecture and that the bacterial lineages are genomic lineages. We focused on two unusual genomic changes: a deletion at a new recombination hotspot composed of long approximate repeats; and a 275 kilobase single block duplication belonging to a new class of genomic duplications.

Conclusion: Our findings demonstrate that major genomic variations occur in Photorhabdus clonal populations. The phenotypic consequences of these genomic changes are cryptic. This study provides insight into the field of bacterial genome architecture and further elucidates the role played by clonal genomic variation in bacterial genome evolution.
\end{abstract}

\section{Background}

Comparative genomics, in the study of different bacterial gen- era, species, and strains, leads to the definition of two DNA pools in bacterial genomes: a set of genes shared by all 
genomes in a taxa, namely the 'core' genome; and a set of genes containing mobile and accessory genetic elements, termed the 'flexible' gene pool. Both intergenomic and intragenomic rearrangements occur in this 'flexible' gene pool [1]. Changes in the 'flexible' gene pool are considered to be the motor of bacterial diversification and evolution [2-4].

However, comparative genomic analyses of genomic variants within a clonal population are rarely undertaken because of the difficulties involved in using molecular approaches in a mixed population. Initially, researchers focused on local modifications of the DNA sequence occurring during phase variation. Phase variation is an adaptive process by which certain bacteria within a bacterial subpopulation, called phase variants, undergo frequent and reversible phenotypic changes. Phase variation is dependent on DNA sequence plasticity, generating a reversible switch between 'on' and 'off' phases of expression for one or more protein-encoding genes. Variation in the expression of certain genes in some phase variants allows the bacterial population to adapt to environmental change [5-7]. Other studies have focused on DNA sequence variations that involve large regions of the genome in a clonal population. These extensively distributed and large genomic rearrangements mostly occur through homologous recombination between repeated sequences such as rrn loci, duplicated genes, or insertion sequences, which may then lead to the inversion, amplification, or deletion of chromosomal fragments. These events can occur either under strong selective pressure - such as in vitro antibiotic selection [8], stressful high temperature [9], long-term storage [10-12], and chronic clinical carriage [13] - or without specific selective pressure [14-20].

The phenotypic consequences of such large rearrangements are variable. In Streptomyces spp., genetic instability affects various phenotypical properties, including morphological differentiation, production of secondary metabolites, antibiotic resistance, secretion of extracellular enzymes, and gene expression for primary metabolism, regardless of selective pressure [20]. In other bacterial species and when stressful selective pressure is applied, large-scale genomic variation often correlates with modification of certain phenotypes: reversion from nutritional auxotrophy to prototrophy [10], variation in colony morphology [11], modification of bacterial growth features [12], and adaptation to high temperature [9]. Few data are available on phenotypic variation in the absence of strong selective pressure. A few studies suggest that large genomic architecture modifications can occur with or without slight detectable phenotypic modifications $[15,16]$. We studied genomic rearrangements in the entomopathogenic bacterium Photorhabdus luminescens, for which variants are frequently observed in standard growth conditions, in order to investigate further the link between genomic variation within a bacterial population and the phenotypic consequences.
$P$. luminescens is a member of the Enterobacteriaceae; it is a symbiont of entomopathogenic nematodes and is pathogenic for a wide variety of insects [21-24]. Bacterial variants frequently arise within the Photorhabdus genus. Two types of variant exist. The phenotypic variants (PVs) are the most studied. The primary PV is characterized by the presence of numerous phenotypic traits (production of extracellular enzymes, pigments, antibiotics, crystalline inclusion bodies, and ability to generate bioluminescence) that are absent from the secondary PV. Secondary PVs are mostly obtained during prolonged in vitro culturing [25,26]. Only primary PVs support nematode growth and development both in the insect cadaver and in vitro. However, both variants are equally virulent to insect hosts [27]. This phenomenon differs from classical phase variation because it occurs at low and unpredictable frequency, it is rarely reversible, and numerous phenotypic traits are altered simultaneously [27]. Recent studies suggest that generation of PVs in P. luminescens may be controlled by several regulatory cascades, each of them involving the products of many different genes [28-31].

The other common variants in Photorhabdus are colonial variants (CVs). Different colonial morphotypes can be generated from one colony subculture. This variation is unstable; indeed, each morphotype can generate all other morphotypes [32-36]. The most frequent CVs are small-colony variants (SCVs). These SCVs constitute a slow-growing bacterial subpopulation with atypical colony morphology and unusual biochemical characteristics that, in the case of clinical isolates, cause latent or recurrent infections [37]. In Photorhabdus, these SCVs can be generated from primary or secondary PV [34]. SCVs have small cells, do not produce crystalline inclusions [32-34], and have undergone changes in their proteome [33,34]. Some SCVs have modified virulence properties and do not support nematode development and reproduction [32].

Previous studies, incorporating local genetic [28,38,39] or nonexhaustive genomic comparisons [33,34,40,41], have not identified genomic differences within sets of PVs or CVs. We used the recently elucidated complete nucleotide sequence of the $P$. luminescens subspecies laumondii strain TTo1 [42] to study systematically the link between phenotypic and genomic variations in clonal Photorhabdus variants. We undertook whole-genome comparisons between the wildtype TTo1 strain and six different PVs or CVs. We showed that large genomic rearrangements occurred in vivo and in vitro. We described two categories of intragenomic rearrangements: deletion events occurring in the 'flexible gene pool', and an unusual duplication of a 275 -kilobase $(\mathrm{kb})$ region, encompassing $4.8 \%$ of the TTo1 wild-type genome. These rearrangements were not correlated with the generation of PVs, and we did not detect a functional relationship between the genes affected by rearrangements and phenotypic variation. Thus, the consequences of these genomic changes are cryptic. 


\section{Results}

TTO $\alpha_{/ /}$: a genomic variant isolated from the laboratory-maintained nematode Heterorhabditis bacteriophora

The nematode Heterorhabditis bacteriophora THo1, harboring the TTo1 wild-type strain, was collected in Trinidad in 1993 [43]. The nematode was maintained in the laboratory and multiplied by infestation in the Lepidopteran Galleria mellonella [44]. In 1998, a further bacterial isolate was taken from this nematode. During the course of a genetic study of the type III secretion system, we discovered that the bacterium isolated in 1998 is a genomic variant. It differs from the TTo1 wild-type strain by a 250 base pair deletion at the 5 ' end of the gene lopT1 (Additional data file 1). This gene encodes a type III secretion system effector that appears to be involved in the depression of the insect innate immune system [45]. Both TTO1 wild-type and the lopT1 genomic variant produced many of the phenotypes associated with primary PVs, including bioluminescence, lipase activity, antibiotic production, and presence of cytoplasmic crystal (Table 1). Therefore, both were primary PVs. To distinguish between them, the TTo1 wild-type strain was named TTo1/I and the $\operatorname{lopT}_{1}$ genomic variant, TTo1 $\alpha_{/ \mathrm{I}}$ (Figure 1).

\section{Isolation and characterization of PVs and CVs from TTO I / $_{\text {and }}$ TTO I $\alpha_{/ /}$}

We cultured TTO1/I and TTo1 $\alpha_{/ \mathrm{I}}$ in liquid broth and selected primary and secondary PVs on NBTA (nutrient agar supplemented with bromothymol blue and triphenyl 2,3,5 tetrazolium chloride) plates. TTo1/II secondary PV was derived from TT01/I (TTo1 lineage; Figure 1). TTo1 $\alpha_{/ \mathrm{II}}$ and TTo1 $\alpha^{\prime} / \mathrm{II}$ secondary PVs were obtained from TTo1 $\alpha_{/ \mathrm{I}}$ (TTo1 $\alpha$ lineage; Figure 1). TTo1/II ${ }^{\text {TTo1 }} \alpha_{/ \mathrm{II}}$, and TTo1 $\alpha_{/ \mathrm{II}}$ had classic secondary PV traits (Table 1).
We developed a new agar medium, the TreGNO (nutrient agar with trehalose and and bromothymol blue) medium, for color discrimination of TTo1 PVs (see Materials and methods [below] for details). PVs produce green, convex, and mucoid colonies whereas secondary PVs produce yellow, flat, and nonmucoid colonies on this medium. TTo $1_{/ \mathrm{II}}$ and TTo1 $\alpha_{/ \mathrm{II}}$ colonies were homogeneous and had the colonial traits of secondary PVs. However, TTo1 $\alpha^{\prime} / \mathrm{II}$ was composed of three CVs (TTo1 $\alpha^{\prime}$ lineage; Figure 1). The first was a primary colonial form (green, convex, and mucoid colonies), named REV because it resembled a revertant colony, exhibiting primary PV traits (although bioluminescence, pigmentation, and crystal production were not completely restored; Table 1). The second was a secondary colonial form (yellow, flat, and nonmucoid colonies), named VAR because of its secondary PV traits (Table 1). The third form had small, green, convex, and mucoid colonies, and was named INT because of its intermediate traits or traits from both the primary and secondary PVs (Table 1). These CVs are unstable because each individual TTo1 $\alpha^{\prime} /$ II colony grown in liquid broth gives rise to a mixture of the three colonial forms on TreGNO medium. We generated a stable secondary PV from the VAR colonial variant by plating a liquid subculture from an individual VAR colony on nutrient agar and picking another VAR colony for a new cycle of liquid/plate culture. We continued this enrichment process until the liquid subculture generated $95 \%$ of VAR colonies on TreGNO plates. The stable population was named VAR* (Figure 1).

We PCR-amplified the lopT1 5 ' region from TTo $1_{/ \mathrm{II}}$, TTo $1 \alpha_{/ \mathrm{II}}$, $\mathrm{TTO}^{\prime} \alpha^{\prime} / \mathrm{II}, \mathrm{VAR}^{*}$, and REV (Additional data file 1). The lopT1 deletion was only present in the TTo1 $\alpha$ and TTo1 $\alpha$ ' lineages.

Virulence of TTOI variants

We injected TTo1 $/ \mathrm{I}$, TTO1 $_{/ \mathrm{II}}$, TTO $1_{/ \mathrm{I}}, \mathrm{TTO}_{/ \mathrm{II}}$, and VAR* into

Table I

\begin{tabular}{|c|c|c|c|c|c|c|c|c|c|}
\hline Phenotype & $\mathrm{TTOI}_{/ /}$ & TTOI $\alpha_{/ /}$ & $\mathrm{TTOI}_{/ 1 \mathrm{I}}$ & TTOI $\alpha_{/ I I}$ & TTOI $\alpha_{/ I I}^{\prime}$ & VAR & VAR* & REV & INT \\
\hline Bioluminescence & + & + & - & - & - & - & - & $+/ w$ & $w$ \\
\hline Colony morphology & $\begin{array}{l}\text { Convex, } \\
\text { mucoid, }\end{array}$ & $\begin{array}{l}\text { Convex, } \\
\text { mucoid, }\end{array}$ & $\begin{array}{l}\text { Flat, } \\
\text { nonmucoid }\end{array}$ & $\begin{array}{l}\text { Flat, } \\
\text { nonmucoid }\end{array}$ & $\begin{array}{l}\text { Flat, } \\
\text { nonmucoid }\end{array}$ & $\begin{array}{l}\text { Flat, } \\
\text { nonmucoid }\end{array}$ & $\begin{array}{l}\text { Flat, } \\
\text { nonmucoid }\end{array}$ & $\begin{array}{l}\text { Convex, } \\
\text { mucoid }\end{array}$ & $\begin{array}{l}\text { Small, convex, } \\
\text { mucoid }\end{array}$ \\
\hline $\begin{array}{l}\text { Lipase activity on } \\
\text { Tween } 20-60\end{array}$ & ++ & ++ & + & + & + & + & + & ++ & ND \\
\hline $\begin{array}{l}\text { Lipase activity on } \\
\text { Tween } 80-85\end{array}$ & ++ & ++ & $+/ w$ & $+/ w$ & $+v$ & + & v & ++ & ND \\
\hline Pigmentation & $+($ Orange $)$ & $+($ Orange $)$ & $+($ Yellow $)$ & $++($ Yellow $)$ & - & - & - & $+($ Orange $)$ & ND \\
\hline $\begin{array}{l}\text { Antibiotic } \\
\text { production }\end{array}$ & + & + & - & - & - & - & - & $+/ w$ & ND \\
\hline Crystal proteins & + & + & - & - & - & - & - & $w$ & - \\
\hline $\begin{array}{l}\text { Coloration on } \\
\text { TreGNO medium }\end{array}$ & Green & Green & Yellow & Yellow & Yellow & Yellow & Yellow & Green & Green \\
\hline
\end{tabular}

+, positive; -, negative; v, variable; w, weak. 


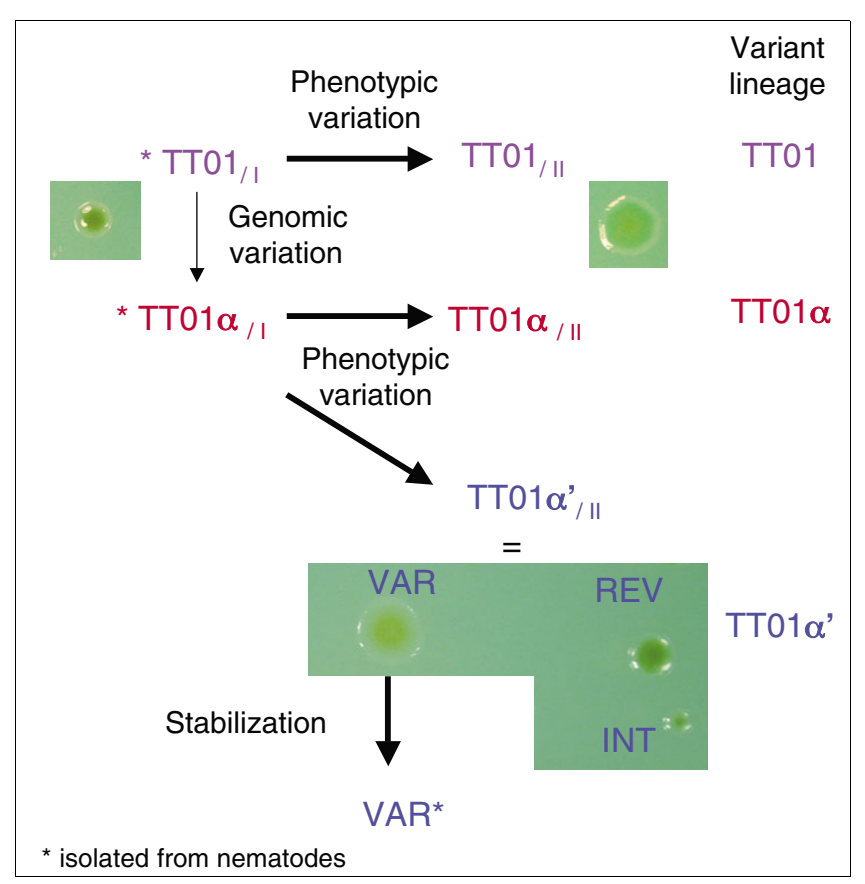

\section{Figure I}

Schematic representation of TTOI variants selection on TreGNO medium. $\mathrm{TTOI}_{/,}, \mathrm{TTO} \alpha_{/ /}$, and REV colonies are green, convex, and mucoid colonies; $\mathrm{TTOI}_{/||}, \mathrm{TTOI}_{/ / \mathrm{l}}, \mathrm{VAR}$, and VAR* colonies are yellow, flat, and nonmucoid; and the INT colonies are small, green, convex, and mucoid.

Spodoptera littoralis larvae to evaluate the pathogenicity of these variants in insect larvae. TTo $1_{/ \mathrm{II}}$, TTo1 $\alpha_{/ \mathrm{I}}$, and TTo1 $\alpha_{/ \mathrm{II}}$ had the same level of pathogenicity as TTo1/1; $50 \%$ mortality $\left(\mathrm{LT}_{50}\right)$ was reached between 28 and 32 hours after injection for the TTo1 wild-type strain and these three variants. By contrast, $\mathrm{VAR}^{*}$ had a delayed $\mathrm{LT}_{50}$ of 53 hours, although $100 \%$ mortality was reached at 3 days after infection (Figure 2).

\section{Extensive rearrangements in genomic architecture correlated with the variant lineages}

We examined the whole genome architecture of each variant using I-CeuI genomic macrorestriction and pulsed field gel electrophoresis (PFGE) in order to detect large rearrangement such as deletions and amplifications by recombination between $r r n$ or deletions, amplifications, and translocations inside I-CeuI fragments. I-CeuI is an intron-encoded enzyme that specifically cleaves a 26-base-pair site in the bacterial 23S rRNA gene. The PFGE pattern obtained for the TTo1/I strain matched the pattern of I-CeuI fragments predicted from the complete TTo1/I genome sequence (Figure 3a, b; also see Additional data file 2 for the details of the gels). Using the TTo1/I pattern used as a reference, we observed large genomic rearrangements in TTo1 $\alpha_{/ \mathrm{I}}$, TTo1 $\alpha_{/ \mathrm{II}}$, TTo1 $\alpha_{\mathrm{II}}^{\prime}$, VAR $^{*}$, and REV. PFGE patterns revealed identical profiles for primary and secondary PVs within both TTo1 and TTo1 $\alpha$ lineages (Figure $3 \mathrm{~b}$ and Additional data file 2). Therefore, PV status (primary versus secondary) in these variant lineages is independent from global genomic architecture.

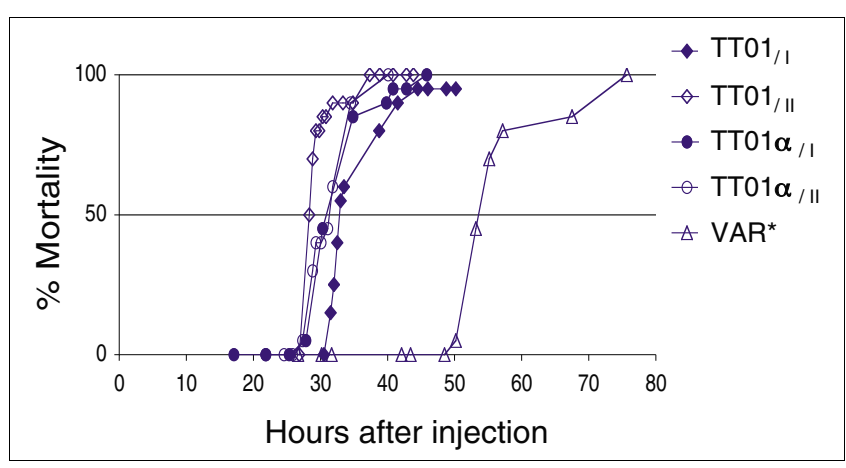

Figure 2

Mortality in Spodoptera littoralis. Shown is the mortality in S. littoralis

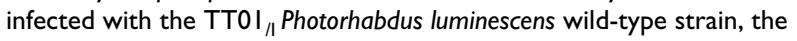
genomic variant TTO I $\alpha_{/ \mid}$, the secondary variants TTOI $\mathrm{I}_{/ \mid}$and TTO $\alpha_{/||}$, and the stabilized $\mathrm{VAR}^{*}$ colonial variant. Bacteria obtained at the end of the exponential phase were injected into fourth-instar larvae. Mortality values are based on data obtained after injection into 20 larvae. All experiments were repeated at least twice.

Cluster analysis of the seven observed I-CeuI patterns reveals that variant lineages are in fact genomic lineages (Figure 3c). The TTo1 and TTo1 $\alpha$ lineages exhibit genomic homogeneity. The TTo1 $\alpha$ lineage shared common genomic features with the TTo1 $\alpha$ lineage, but exhibited a more polymorphic genomic pattern than TTO1 and TTo1 $\alpha$ lineages.

The PFGE patterns of TTo1 $\alpha$ and the TTo1 $\alpha$ lineages only reveal six apparent I-CeuI fragments, instead of seven fragments in the TTo1/I reference chromosome; however, the intensity of the 295-kb band suggests that it may represent two different fragments. We used Southern blot analysis to confirm that the seven rrn copies are present in all the variants (Additional data file 3). Therefore, variation in I-CeuI PFGE patterns among the TTo1 variants appeared to be unrelated to deletion or amplifications mediated by recombination between $r r n$ operons.

Additionally, the $465 \mathrm{~kb}$ faint band in the TTo1 $\alpha^{\prime} /$ II pattern (white star in Additional data file 2) corresponded to a fragment in the REV pattern, suggesting the existence of a 'REVlike' chromosome subpopulation in TTo1 $\alpha_{/ \mathrm{II}}$.

\section{Deletions and amplifications in the TTO I $\alpha_{/ 1}$ and VAR* variants, representative of the TTOI $\alpha$ and TTOI $\alpha^{\prime}$ lineages}

Large genomic rearrangements were present in the TTo1 $\alpha$ and TTo1 $\alpha^{\prime}$ lineages. We further evaluated the nature of these rearrangements by comparing gene content between representative variants of each lineage, TTo $/ / \mathrm{I}, \mathrm{TTO}_{/} \alpha_{/ \mathrm{I}}$ and $\mathrm{VAR}^{*}$, using genomic DNA hybridization on a $P$. luminescens TTo1/I microarray.

Totals of 159 and 162 genes were absent from TTo1 $\alpha_{/ \mathrm{I}}$ and $\mathrm{VAR}^{*}$, respectively (see Additional data file 4). We located these genes on a circular map of the TTo1/I chromosome (Fig- 


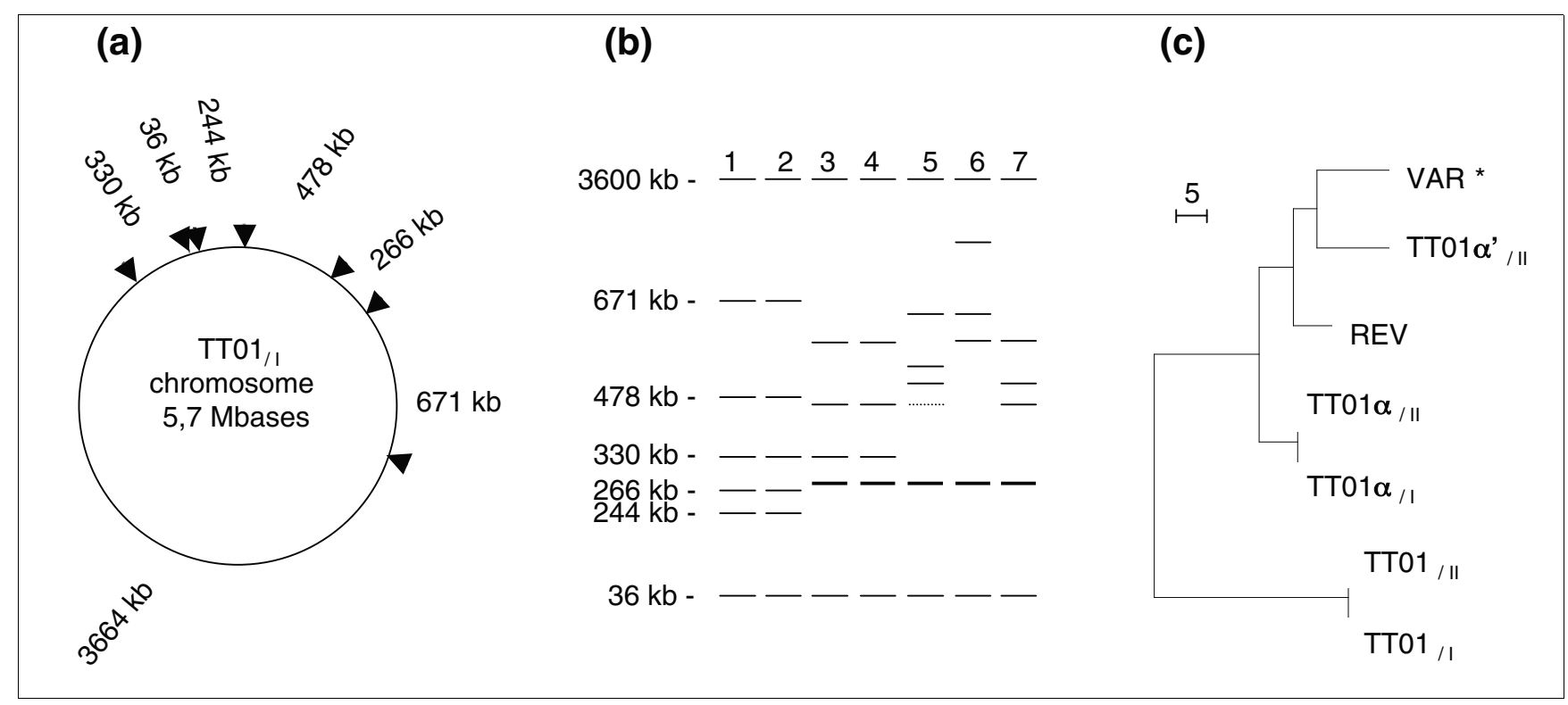

Figure 3

Variation in genomic architecture of the TTOI variants. (a) Schematic representation of the I-Ceul restriction map of the TTOI // Photorhabdus luminescens reference genome. (b) Schematic reconstruction of I-Ceul pulsed field gel electrophoresis (PFGE) patterns for TTOI $/ /$ and the six variants representing gels presented in Additional data file 2. Fragment sizes were calculated using the TTOI /, genome as a reference. Lane I: TTOI/|. Lane 2: TTOI /I. Lane 3: TTOI $\alpha$,

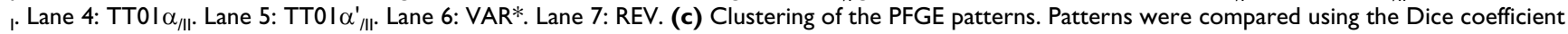
for each pair. Patterns were clustered by UPGMA.

ure 4); they mostly clustered into eight regions absent from both the TTo1 $\alpha_{/ \mathrm{I}}$ and VAR* genomes (regions A, C, D, E, F, G, $\mathrm{I}$, and $\mathrm{J}$ ) and one region specifically absent from the $\mathrm{VAR}^{*}$ genome (region $\mathrm{H}$ ). The deleted regions were located throughout the chromosome, with no particular symmetry around the replication origin or termination site. Several regions displayed a GC bias inversion $(\mathrm{C}, \mathrm{D}, \mathrm{E}, \mathrm{G}, \mathrm{I}$, and $\mathrm{J}$ ). Three overlapped with phagic regions (C, G, and I), suggesting that prophage excision occurred during the TTo $1_{/ \mathrm{I}}$ to $\mathrm{TTO} \alpha_{/ \mathrm{I}}$ transition (Table 2). As well as phagic genes, the deleted regions encompass putative mobile and recombination-mediating elements such as insertion sequences and recombination hotspot (Rhs) elements (region A), and plasmid-related protein-encoding genes (region J)(Table 2). The regions $\mathrm{C}, \mathrm{D}, \mathrm{E}$, and $\mathrm{F}$ potentially encode peptide synthetases involved in antimicrobial compound synthesis (Table 2). However, we did not observe any significant difference in antimicrobial activity between TTO1/I and TTo1 $\alpha_{/ \mathrm{I}}$ tested for 14 indicator strains (data not shown).

A more thorough analysis of hybridization ratios revealed that 122 genes had a ratio higher than 1.4 in the VAR ${ }^{*}$ genome (Additional data file 5). In contrast, comparison of the TTO1/I and $\mathrm{TTO}_{\alpha} \alpha_{\mathrm{I}}$ genomes revealed only four genes with a ratio higher than 1.4. These findings suggest that numerous genes are amplified in the $\mathrm{VAR}^{*}$ genome. Among these potentially amplified genes, 112 are clustered in a unique and large 275$\mathrm{kb}$ region, named $\mathrm{B}$. This region encompasses $4.8 \%$ of the $\mathrm{TTo1}_{/ \mathrm{I}}$ genome (from pluo769 $=m r f A$ to pluog8o $=h p a A$;
Figure 4). Region B is located within the first quarter of the TTO1/I $_{\text {I }}$ chromosome and is not delimited by obvious repeat elements. According to TTo1 $/ \mathrm{I}$ genome annotations, the region $\mathrm{B}$ may be involved in numerous and different functions (Table 2): basal cellular functions involving the DNA polymerase III $\varepsilon$ chain (pluo943 = dnaQ), enolase (pluo913 = eno), and proteins involved in tryptophan metabolism (pluo799 = tnaA; pluo8oo = mtr); and environment and/or host interactions, involving the major fimbrial biosynthesis locus (pluo769-0778 = the mrfABCDEFGHJ operon), insecticidal toxin proteins (pluo8o5 = tccA3; pluo8o6 = tccB3; plu0960 = tcc2; plu0961 = tcdB1; plu0962 = tcdA1; plu0964 $=t c c C_{5} ;$ pluo965 = tcdA4; plu0970 = tcdB2; plu0971 = tcdA2), and proteins similar to pyocins (pluo884; pluo886o888; pluo892; pluo894).

To determine whether DNA microarray experiments explain the architectural modifications observed by macrorestriction experiments, we compared the two sets of data. The observed I-CeuI macrorestriction fragments from the TTo1 $\alpha$ lineage (36 kb, 295 kb, 295 kb, 330 kb, 465 kb, 610 kb, 360o kb) were similar to the theoretical I-CeuI fragments calculated after size subtraction of the eight deleted regions from the TTo1/I I-CeuI fragments (36 kb, 244 kb, 266 kb, 330 kb, 462 $\mathrm{kb}, 627 \mathrm{~kb}, \sim 3478 \mathrm{~kb})$. Therefore, large-scale deletion events appear to underlie the TTO1 to TTo1 $\alpha$ lineage transition. DNA microarray experiments in the TTo1 $\alpha$ ' lineage identified a 275 $\mathrm{kb}$ amplification of the TTo1/I genome. Duplication or triplication of region $\mathrm{B}$ may account for the increase in genome size 
Table 2

\begin{tabular}{|c|c|c|c|c|c|}
\hline Locus & $\begin{array}{l}\text { Probable nature } \\
\text { of event }\end{array}$ & Gene region & Size (in kb) & Products of interest (similarity or function) & Matching $\mathrm{Gl}^{\mathrm{a}}$ or $\mathrm{EVR}^{\mathrm{b}}$ \\
\hline A & Deletion & plu0338-plu0355 & 18 & $\begin{array}{l}\text { DNA cytosine, ethyl-transferase, mismatch } \\
\text { repair endonuclease, unknown proteins, Rhs } \\
\text { proteins, IS } 630 \text { family }\end{array}$ & Part of GI plu03 I0-plu0373 \\
\hline B & Amplification & plu0769-plu0980 & 275 & $\begin{array}{l}\text { Proteins involved in basal metabolism (DNA } \\
\text { polymerase III } \varepsilon \text { chain, enolase, tryptophan } \\
\text { metabolism) and in interaction with } \\
\text { environment and/or host (fimbrial biosynthesis, } \\
\text { Tc insecticidal toxins, pyocins) }\end{array}$ & $\begin{array}{l}\text { Encompassed GI plu0884-plu090 I, GI } \\
\text { plu09I4-plu0938, and overlapped a } \\
\text { part of GI plu0958-plu I I } 66\end{array}$ \\
\hline C & Deletion & plu 1086-pluII 23 & 44 & $\begin{array}{l}\text { Unknown proteins, phage regulators, peptide } \\
\text { synthetase, transposase, bacteriophage } \\
\text { proteins }\end{array}$ & Part of GI plu0958-plu I 166 \\
\hline D & Deletion & plu I86I-plu I 876 & 12 & Antibiotic biosynthesis & Part of GI plu I859-plu I 894 \\
\hline $\mathrm{E}$ & Deletion & plu2191-plu2200 & 11 & Antibiotic synthesis and transport & Part of EVR plu2179-plu2224 \\
\hline $\mathrm{F}$ & Deletion & plu2468-plu2476 & 8 & $\begin{array}{l}\text { unknown protein, } A B C \text { transporter, toxoflavin } \\
\text { biosynthesis, transposase }\end{array}$ & EVR plu2468-plu2476 \\
\hline G & Deletion & plu2874-plu2960 & 54 & Bacteriophage proteins & Part of GI plu2873-plu3038 \\
\hline $\mathrm{H}$ & Deletion & plu3238-plu3252 & 22 & Unknown proteins, VgrG proteins & Part of GI plu3207-plu3275 \\
\hline I & Deletion & plu3380-plu3504 & 89 & Bacteriophage proteins & Part of GI plu3379-plu3538 \\
\hline J & Deletion & plu4324-plu4328 & 12 & Unknown and plasmid-related proteins & EVR plu4319-plu4332 \\
\hline
\end{tabular}

a Genomic islands described in [42]. b Enterobacterial variable regions described in [56].

( $100 \mathrm{~kb}$ to $650 \mathrm{~kb}$ ) observed by macrorestriction for the TTo1 $\alpha$ to TTo1 $\alpha$ ' transition. Therefore, duplication appears to be mainly responsible for the TTo1 $\alpha$ to TTo1 $\alpha$ ' lineage transition.

\section{Homologous recombination between long repeats led to serial deletions of the region $\mathrm{H}$ in the TTOI $\alpha$ and TTOI $\alpha$ ' lineages}

We first examined the genomic deletions observed in the $\mathrm{TTO} \alpha / \mathrm{I}$ and $\mathrm{VAR}^{*}$ variants. We focused on region $\mathrm{H}$, which, by contrast to other deleted regions, did not exhibit typical recombination-mediating elements. Probes targeting different parts of the region $\mathrm{H}$ were hybridized on genomic DNA of the wild-type strain and the six variants. Hybridization patterns were identical within each variant lineage and confirmed the presence of a $25 \mathrm{~kb}$ deletion within the region $\mathrm{H}$ (from plu3237 to plu3253) for the TTo1 $\alpha^{\prime}$ lineage (data not shown). Southern analysis also indicated the presence of a small deletion of about $10 \mathrm{~kb}$ (from plu3238 to plu3248) in the TTo1 $\alpha$ lineage. To map the deletion borders accurately, primers flanking the 25 -kb deletion (R-3236 and F-3254) and the 10-kb deletion (R-3238bis and F-3249) were designed (Figure 5) and used for PCR amplification in the TTo1 $\alpha$ ' and TTo1 $\alpha$ lineages. Amplified fragments of $4.8 \mathrm{~kb}$ and $5.2 \mathrm{~kb}$ were observed (data not shown). These fragments were sequenced for TTo1 $\alpha_{/ \mathrm{I}}$ and $\mathrm{VAR}^{*}$, and the deletion was physically mapped (a genetic map of the region $\mathrm{H}$ is presented in Figure 5). The deletions in TTo1 $\alpha_{/ \mathrm{I}}$ and $\mathrm{VAR}^{*}$ were 12,820 bases (from coordinates 3,833,904 to 3,846,723) and 25,140 bases long (from coordinates $3,830,001$ to $3,855,140$ ), respectively.
We used Nosferatu, software that can detect approximate repeats in large DNA sequences [46]. The region $\mathrm{H}$ is rich in pairs of repetition units (RPT) larger than $1 \mathrm{~kb}$ (Figure 5). Each deletion began at the right-hand extremity of the first repetition and finished at the right-hand extremity of the corresponding second repetition (RPT179385 repetitions for the 10-kb deletion and RPT 179383 repetitions for the 25 - $\mathrm{kb}$ deletion). Therefore, successive deletions mediated by homologous recombination between RPT are likely to have occurred in the region $\mathrm{H}$ during the $\mathrm{TTO}_{/ \mathrm{I}}$ to $\mathrm{TTO}_{\alpha / \mathrm{I}}$ to $\mathrm{VAR}^{*}$ transition, leading to genomic reduction.

\section{A single block duplication of region $B$ is specific to the TTO I $\alpha$ ' lineage}

In a second set of analyses, we focused on the gene amplification observed in region B, occurring in the TTo1 $\alpha_{/ \mathrm{I}}$ to VAR transition. Quantitative PCR was performed for two genes in region B, mrfA (pluo769) and dnaQ (plu0943). Comparison of VAR and TTo1 $\alpha_{/ \mathrm{I}}$ data confirmed that these two genes were duplicated in the VAR* genome (Figure 6a).

In order to determine whether region $\mathrm{B}$ is duplicated specifically in the $\mathrm{VAR}^{*}$ variant or in all variants of the TTo1 $\alpha^{\prime}$ lineage, a probe covering the entire region $\mathrm{B}$ (the probe $\mathrm{B}$ ) was prepared and hybridized to genomic DNA of the wild-type strain and the six variants. According to the TTo1/I genome sequence, NotI hydrolysis generates 25 fragments with a unique 1,056-kb fragment containing region B. Hybridization of the probe B to NotI-hydrolyzed genomic DNA generated a unique fragment of $1,056 \mathrm{~kb}$ in the TTo1 lineage and of 1,020 $\mathrm{kb}$ in the TTo1 $\alpha$ lineages (Figure 6b, c). By contrast, in the 


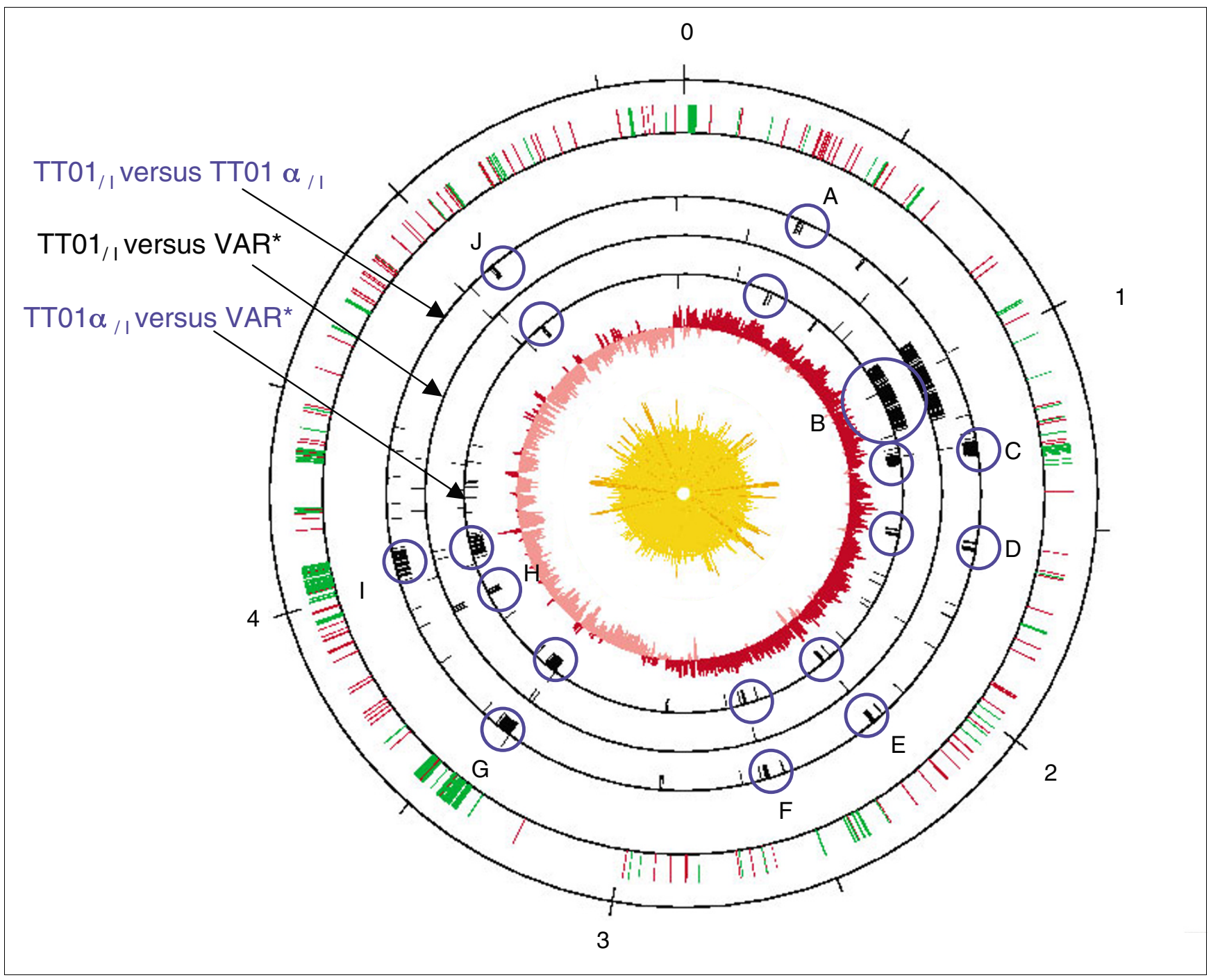

Figure 4

Schematic representation of DNA microarray data as a circular map of the TTOI $/ /$ genome. Circle I (from outside to inside): scale marked in megabases. Circle 2: location of transposases (red) and phage-related genes (green) location. Circles 3, 4, and 5: DNA microarray data comparing TTOI// and TTO I $\alpha_{/ /}$ genomes (circle 3), $\mathrm{TTOI}_{/ /}$and $\mathrm{VAR}^{*}$ genomes (circle 5), and synthesis from both experiments (circle 4). Deleted genes are represented by bars inside the circle. Amplified genes are represented by bars outside the circle. Deleted and amplified regions are circled in blue. Circle 6: GC bias (G-C/G+C). Circle 7: GC content with $<32 \% \mathrm{G}+\mathrm{C}$ in light yellow, between $32 \%$ and $53.6 \% \mathrm{G}+\mathrm{C}$ in yellow, and with $>53.6 \% \mathrm{G}+\mathrm{C}$ in dark yellow.

TTo1 $\alpha$ ' lineage, the B probe hybridized to the $1,020-\mathrm{kb}$ fragment and an additional fragment. This second fragment has a similar size in TTo1 $\alpha^{\prime} / \mathrm{II}$ and VAR* variants $(610 \mathrm{~kb})$ but is smaller $(365 \mathrm{~kb})$ in the REV variant. These findings showed that duplication of region B occurred in all TTo1 $\alpha$ ' lineage variants.

Region B encompasses $275 \mathrm{~kb}$ in the TTo1/I genome sequence; thus, we determined whether the resulting amplified genes were dispersed in the genome or co-localized in an unique block. The unique additional fragment detected by the probe B in the TTo1 $\alpha^{\prime} /$ II and VAR* variants indicated that the product of the region $\mathrm{B}$ amplification is constituted either of one block or a few blocks co-localized in a genomic region whose size is smaller than $610 \mathrm{~kb}$ in TTo1 $\alpha^{\prime} / \mathrm{II}$ and $\mathrm{VAR}^{*}$ and smaller than $365 \mathrm{~kb}$ in REV. The probe B was also hybridized to ApaI-hydrolyzed genomic DNA of the wild-type strain and the six variants. The seven patterns were identical and the probe B hybridized with the two main 74 and $156 \mathrm{~kb}$ fragments covering the major part of region $B$ according to the TTo1/I genome reference sequence (data not shown). Because the duplication did not modify the ApaI restriction pattern, we concluded that region B was amplified as a single block. 


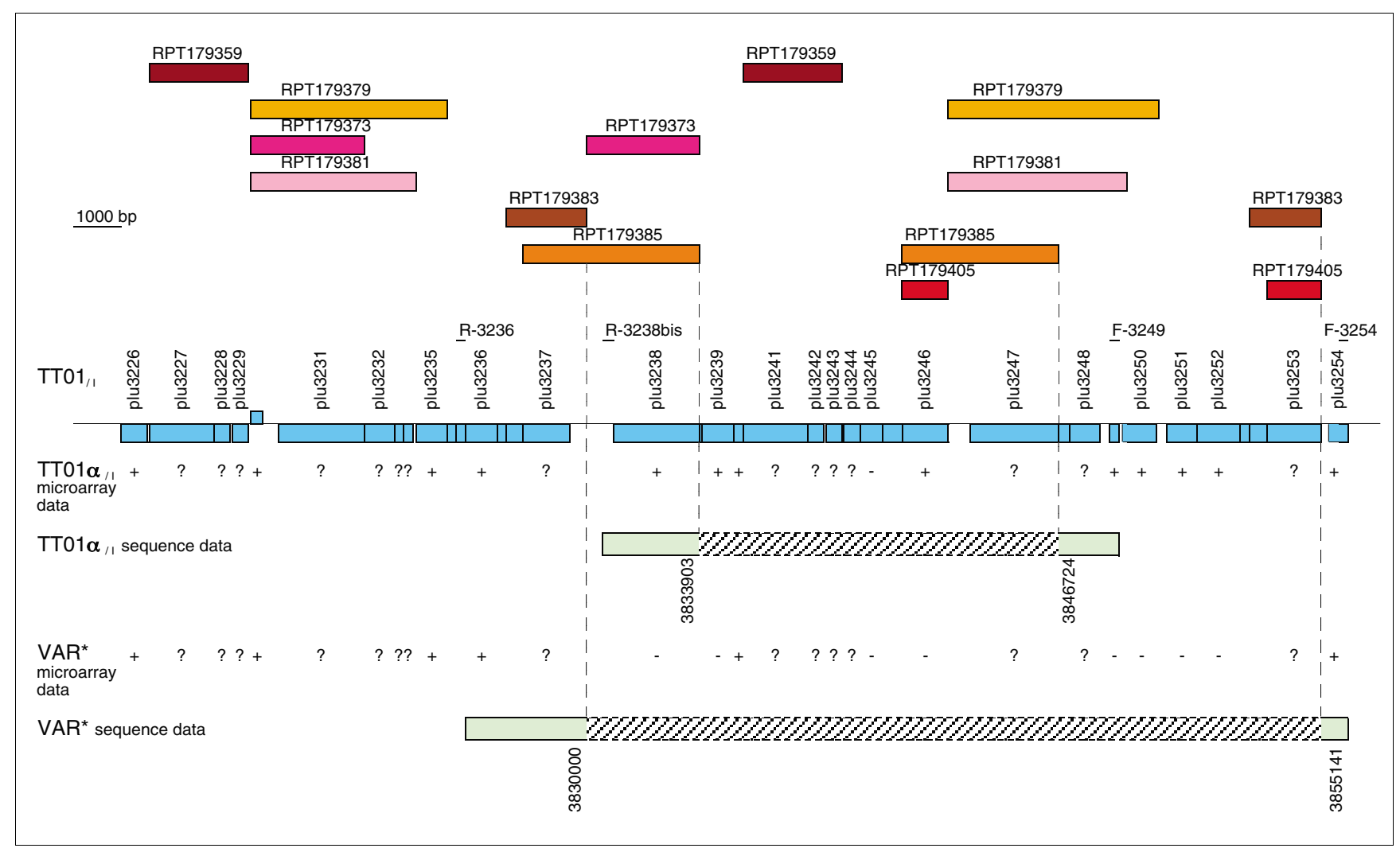

Figure 5

Successive deletions between homologous repeats in the region $\mathrm{H}$. Genetic map of TTOI/, region $\mathrm{H}$ is shown (blue boxes are open reading frames [ORFs]). Location of repetition units (RPT) larger than I kilobase $(\mathrm{kb})$ is indicated (hatched colored boxes). RPT were systematically searched on the whole TTO II genome sequence by using Nosferatu, software that can detect approximate repeat sequences [46]. The RPTs are numbered according their position on the chromosome. DNA microarray data for the TTOI $\alpha / \mid$ and VAR* genomes are indicated. ' + ': the gene is present. '-': the gene is absent. '?': the gene is not represented on the microarray. Schematic representation of TTOI $\alpha_{/ /}$and the VAR* variant deletions is shown. Deletion borders were obtained from sequencing between the R-3236 and F-3254 primers in the VAR* variant, and between the R-3238bis and F-3249 primers in the TTOI $\alpha / /$ variant. Green and hatched gray boxes represent regions in TTOI $\alpha_{/ /}$and VAR* genomes variants that were found to be present or absent, respectively. The deleted regions encompassed sequence between coordinates 3.833 .904 and 3,846,724 in TTOI $\alpha /$ genome and coordinates 3,830,00I and 3,855, I4I in VAR* genome.

\section{Discussion \\ Variant lineages are genomic lineages characterized by extensive genomic rearrangements}

Our study provides the first extensive investigation into genomic rearrangements in Photorhabdus variants. First, we evaluated phenotypic traits of the three variant lineages (Figure 1). The TTo1 lineage is derived from the TTo1/I strain, which was isolated from the $H$. bacteriophora THo1 nematode collected in Trinidad in 1993 [43] and whose genome is sequenced [42]. The TTo1 $\alpha$ lineage is derived from the TTo1 $\alpha_{/ 1}$ genomic variant, which was collected from $H$. bacteriophora THo1 maintained and multiplied in the laboratory. The TTo1 $\alpha$ ' lineage was derived from the TTo1 $\alpha_{/ \mathrm{I}}$ variant after prolonged culture in synthetic medium. Each lineage is composed of PVs, whereby the primary form is characterized by the presence of typical phenotypic traits that are absent from the secondary form. The TTo1 $\alpha$ ' lineage has an additional level of complexity, because the PVs exhibit features of CVs such as unstable morphotypes.
We then examined the genomic architecture of each variant in macrorestriction experiments and used comparative DNA microarray hybridization experiments to analyze the genomic content of representative variants for each lineage. Our findings revealed that large genomic rearrangements characterize each variant lineage. Consequently, these findings provide insight into probable scenarios underlying each lineage transition. The whole-genome organization of the TTo1 lineage is described by the TTo1 reference genome [42]. Largescale deletion events in the TTo1 flexible gene pool seem to be involved in the TTO1 to TTO1 $\alpha$ lineage transition. Deletion events in the TTo1 flexible gene pool and a single block duplication encompassing $4.8 \%$ of the TTo1 reference genome appear to underlie the TTO1 to TTo1 $\alpha$ ' lineage transition. The genomic clusters do not depend on the PV status (see below). Thus, each variant lineage is a genetic lineage. 


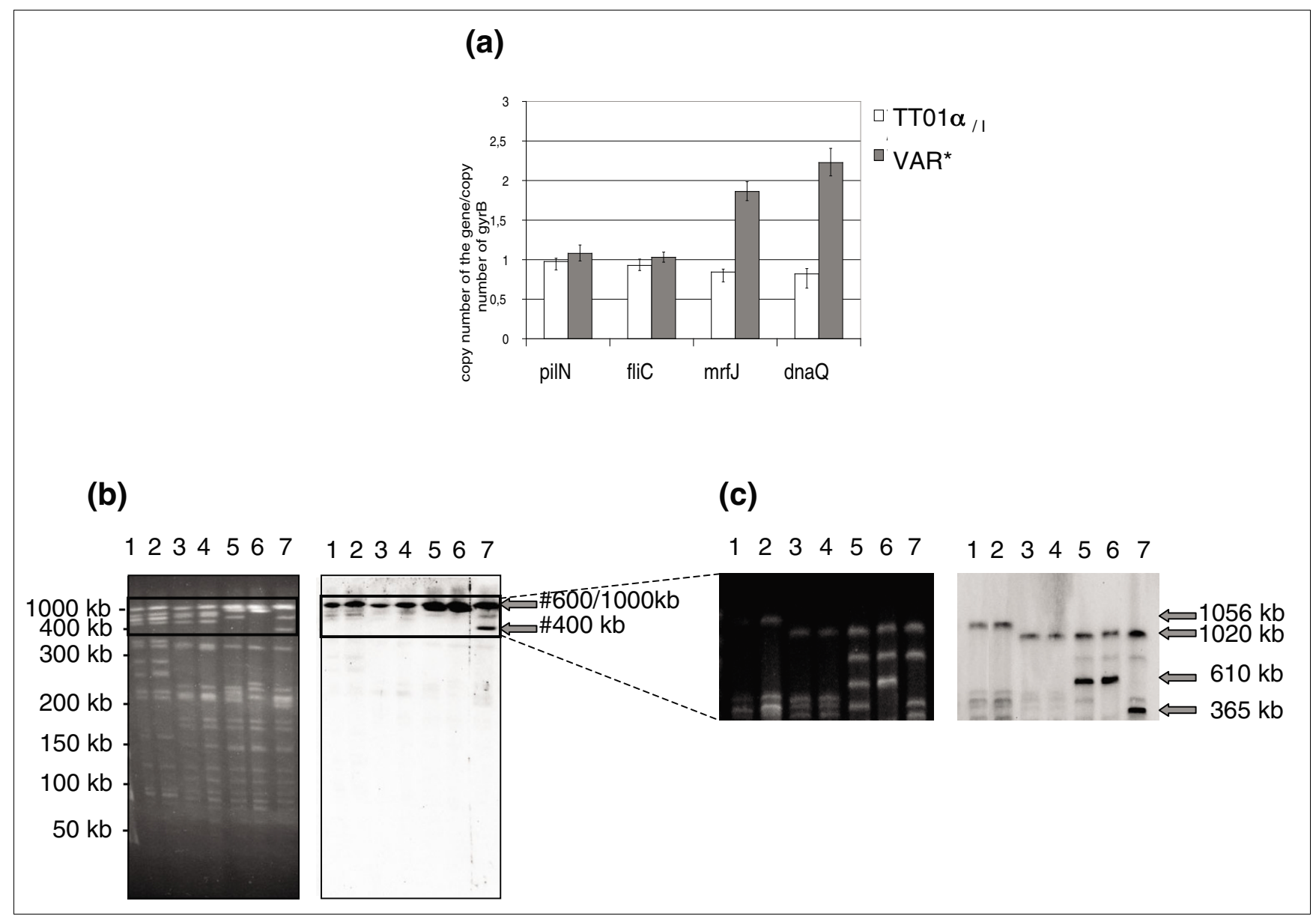

\section{Figure 6}

Duplication of region B. (a) Quantitative PCR was carried out for mrfA (plu0769) and dnaQ (plu0943) using genomic DNA from TTO I $\alpha / /$ and VAR* variants and specific internal primers for each gene. pilN (plu I05I) and fliC (plu I 954) were used for negative controls. PCR was performed in triplicate and data are presented as ratios, with gyrB as the control gene ( $95 \%$ confidence limits). (b, c) Pulsed field gel electrophoresis (PFGE) of Notl-hydrolyzed genomic DNA from TTOI $\alpha_{/ /}$and the six variants following by Southern blot and hybridization with a probe covering the region B (probe B). The PFGE conditions allow separation of Notl fragments between 50 and $400 \mathrm{~kb}$ (panel b) or between 350 and I,350 kb (panel c). Gray arrows indicate fragments that hybridize with the probe B. Lane I: TTOI/|. Lane 2: TTOI /|| Lane 3: TTOI $\alpha_{/ \mid}$. Lane 4: TTOI $\alpha_{/ \mid l}$. Lane 5: TTOI $\alpha_{/|| l}^{\prime}$ Lane 6: VAR*. Lane 7: REV.

\section{Deletion at new recombination hotspot}

To explain the molecular mechanisms involved in the rearrangements in our variants, we investigated potential repetitive elements and recombination-mediating elements flanking the rearranged regions. Large genomic architectural changes are often driven by homologous recombination between repeated sequences. The nature of the change then depends on the relative orientation, size, and spacing of the repeated sequences [47-50]. Recombination events often occur at the rrn operon in Gram-negative bacteria, such as Salmonella, Rhizobium, Escherichia coli, and Ochrobactrum $[11,13,18,51,52]$. However, despite the variation detected in PFGE analysis of the rrn skeleton for the three variant lineages, we demonstrated that the rearrangements are not the result of $r r n$ recombination.
Apart from homologous recombination, rearrangements can be induced by site-specific recombination, associated with recombination-mediating elements such as mobile elements, or by illegitimate recombination, linked to shortly spaced repeats [49,50]. Most of the deleted regions in the TTo1 $\alpha$ lineage are rich in potential rearrangement-mediating elements, with both repeated sequences - including insertion sequences and Rhs elements - and mobile elements, including phagic and plasmid-related genes.

Genomic annotation of the region $\mathrm{H}$, which underwent successive deletions in the TTo1 $\alpha_{/ \mathrm{I}}$ and $\mathrm{VAR}^{*}$ variants, did not describe the presence of typical repetitive or recombinationmediating elements. The region $\mathrm{H}$ belongs to a large genomic island containing the genes $v g r$ and $h c p$, initially described as genes associated with $R h s$ elements. Rhs elements are repeated sequences in the $E$. coli genome that mediate major 
chromosomal rearrangements [51,53,54]. Although the TTo1, I genome contains $R h s$-like elements [42], no $R h s$ element is located in the genomic island encompassing the region $\mathrm{H}$. Nevertheless, we identified pairs of approximate long repeated sequences $(>1 \mathrm{~kb})$ in direct orientation (RPT) that corresponded to the observed deletion junction points. Therefore, successive deletions in the region $\mathrm{H}$ are likely to have been mediated by homologous recombination between RPT during the transition from $\mathrm{TTO}_{/ \mathrm{I}}$ to $\mathrm{TTO}_{/ \mathrm{I}}$ to $\mathrm{VAR}^{*}$, leading to genomic reduction.

There was a strong selective pressure during the TTo1 $\alpha$ to TTo1 $\alpha^{\prime}$ lineage transition (3 months in LB broth without shaking). This environmental constraint could thus be responsible for the rearrangement leading to the region $\mathrm{H}$ deletion. However, the region $\mathrm{H}$ deletion was already initiated during the former transition (TTo $/ / \mathrm{I}$ to TTo1 $/ / \mathrm{I}$ in the laboratory-maintained nematode). Therefore, the observed reduction genomic size is more likely to be the result of particular genomic features (the RPT) rather than environmental constraints.

The region $\mathrm{H}$ is unique in the TTo1/I genome. Nevertheless, some RPT elements have similarities with sequences elsewhere in the TTo1/I genome, in the Photorhabdus strain W14 genome [55] or in other Enterobacteriaceae genomes such as Yersinia pseudotuberculosis IP32953 (BX936398.1), Yersinia pestis Angola (CPooo901.1), Yersinia pestis Pestoides F (CPoo0668.1), Yersinia pestis CO92 (AL590842.1), Yersinia pestis biovar Microtus str. 91001, (AE017042.1, Yersinia pestis Antiqua (CPooo308.1), Yersinia pestis Nepal 516 (CPoo0305.1), Yersinia pestis KIM (AEoo9952.1), Yersinia pseudotuberculosis IP 31758 (CPoo0720.1), and E. coli CFTo73 (AE014075.1). Therefore, we propose that the region $\mathrm{H}$ represents a new type of bacterial recombination hot spot, which is $v g r$ - and $h c p$-rich, but lacks $R h s$ elements.

\section{A new duplication class}

We described a single block duplication (region B) targeting a $275-\mathrm{kb}$ region of the TTo1/I genome in the TTo1 $\alpha$ lineage. This significant duplication encompasses $4.8 \%$ of the TTo $1_{/ \mathrm{I}}$ genome. Region $\mathrm{B}$ is not located near the replication origin or termination and does not correspond to genomic islands or enterobacterial variable regions previously identified [42,56]. GC content or GC skew deviations are not evident.

Gene amplifications can occur through three kinds of known mechanism: homologous recombination between direct repeats, illegitimate recombination, or escape replication. No repeated elements flanking region $\mathrm{B}$ were detected, despite the use of the Nosferatu software [46], excluding the possibility of homologous recombination underlying this duplication. Region B duplications may result from illegitimate recombination between short repeats $[47,57,58]$. However, amplification copy number resulting from illegitimate recombination events is often high, even for large amplicons, such as in Aci- netobacter sp. ADP1 or Streptomyces kanamyceticus [59,6o]. Escape replication involves amplification of large regions of the host genome (several hundred kilobases), next to phage integration sites after induction of the phage lytic cycle [61-64], or around degraded prophages without the induction of specific phage lysis [65]. Although phage remnants represent $4 \%$ of the Photorhabdus genome [42], lytic phages have not been identified in Photorhabdus strains, even after extensive investigation of lytic induction conditions [66]. We detected the presence of an 11-kb phagic segment (pluo818-pluo826) in region B, potentially representing a degraded prophage. However, whereas the copy number usually resulting from the escape replication mechanism ranges between three and ten, with its intensity decreasing symmetrically from the center, region $B$ in the TTo1 $\alpha$ ' lineage genomes represents a single block homogeneous duplication. We only identified one other previously reported example of a large duplication without repeated flanking sequences - a $250 \mathrm{~kb}$ duplication in Mycobacterium smegmatis $\mathrm{mc}^{2} 155$ genome [67]. Therefore, the duplication of region $B$ is likely to belong to a new class of duplications.

\section{Observed phenotypes and global genomic architecture are not systematically correlated}

Large genomic changes such as deletions and duplications are supposed to have important fitness effects. In our study, we firstly demonstrated that the PV status (primary or secondary) is independent from global genomic architecture. This was consistent with previous studies analyzing specific genetic regions $[28,38,39]$ and with partial genome studies $[33,40,41]$, but this is the first time it has been demonstrated using a whole-genome approach.

We showed that the overall genomic pattern corresponds to the variant lineage. Both the phenotype and pathogenic traits of the primary PV (or the secondary PVs) are indistinguishable between the TTo1 and TTo1 $\alpha$ lineages. Therefore, changes in the genomic architecture of these strains did not lead to observable changes in the phenotype. Furthermore, certain regions that were deleted in the TTo1 $\alpha$ lineage potentially encode biosynthesis pathways for antimicrobial compounds. However, we did not observe any difference in antimicrobial activity between TTo $1_{/ \mathrm{I}}$ and TTo1 $\alpha_{/ \mathrm{I}}$. This finding suggests that some TTo1/1 genes are redundant. Indeed, genes encoding proteins potentially involved in the biosynthesis of antimicrobial compounds are over-represented in TTo $1_{/ 1}$ genome [42]. Moreover, the encoded proteins in the deleted regions may be adaptive factors required for specific conditions that are not encountered in the laboratory or in our antibiosis assays.

The TTo1 $\alpha^{\prime}$ lineage differs from the two other lineages due to its polymorphic genomic pattern. Furthermore, this lineage is composed of three unstable CVs and the virulence of the stabilized VAR* variant is attenuated in insects. This is consistent with previously reports of CVs isolated from the Pho- 
torhabdus genus [33]. Therefore, changes in genomic architecture might be correlated to phenotypic changes in variants of this lineage. The main rearrangement observed in the TTo1 $\alpha$ ' lineage is the region B duplication. According to TTo1/I genome annotation, region B may be involved in both basal cellular functions and environment and/or host interactions. Gene duplication events can underlie modification of phenotypes [58]. However, we did not detect any modification of gene transcription in region $\mathrm{B}$ using transcriptomic microarray comparison between the $\mathrm{VAR}^{*}$ and TTo1 $\alpha / \mathrm{I}$ variants (Gaudriault S, unpublished data). Thus, this duplication does not appear to modify gene expression in the VAR* variant. Therefore, the attenuation of virulence of the $\mathrm{VAR}^{*}$ variant is not likely to be due to amplified expression in region $\mathrm{B}$. Rather, it is more likely that the 'cost' to the bacteria of the increased genome size is decreased virulence in insects.

We conclude that the observed phenotypes and overall genomic architecture are not systematically correlated in TTo1, TTo1 $\alpha$, and TTo1 $\alpha$ lineages. It is likely that this result is general in the field of bacterial genomic architecture. Similar observations were previously made between strains of the Pseudomonas aeruginosa species [68], but also inside a clonal bacterial population of a wide range of bacterial groups such as Yersinia pestis [19], Pseudomonas aeruginosa [17], and Sinorhizobium meliloti [16].

\section{Stability and plasticity of bacterial genome architecture}

Do large genomic rearrangements occur randomly or are they shaped by drastic selective evolutionary forces? Several years of comparative genomics between whole bacterial genomes showed that the prokaryotic genome is a heterogeneous entity, with regions of stability and flexibility [4,49,50]. Genomic stability is subject to selective pressures such as functional replication [69], gene essentiality [70], or translation [71]. The three main routes of evolution of genome repertoire are lateral gene transfer, when several bacterial communities share a same ecological niche, deletions, and duplications $[4,49,50]$. The dynamism of genome repertoire inside a clonal population only arises by the last two phenomena, as illustrated by our study on Photorhabdus variants.

In E. coli, the chromosome is organized in structured macrodomains, limiting genome plasticity. Whereas some genomic rearrangements between these macrodomains have only moderate effects on cell physiology, others have detrimental effects [72]. The rearrangements that we observed in our variants may have been selected to preserve chromosomal configurations that are not detrimental for bacterial fitness in the laboratory or in the nematode. We believe that structured macrodomains that restrict chromosome plasticity are likely to exist in other bacterial genus. Identification of structured macrodomains in $P$. luminescens genome would provide better knowledge on evolutionary forces modeling bacterial genome.

\section{Clonal variation, environmental adaptation, and bacterial evolution}

The major genomic variations described in TTo1 variants have cryptic consequences in our laboratory conditions. The absence of associated phenotypes makes them difficult to identify, explaining why such genomic variations are rarely observed. However, further studies of such genomic variations may be crucial for a better understanding of bacterial adaptation and evolution.

Indeed, we observed that the extensive genomic rearrangements in Photorhabdus variants were often associated with several genomic subpopulations in the same culture. Similar observations were previously made for a $P$. luminescens TTO1/I locus encoding a phage tail-like structure [73] and the mrf locus of the P. temperata strain K122 [74]. In Sinorhizobium meliloti, Yersinia pestis, and Pseudomonas aeruginosa, extensive variations of genome architecture, without obvious changes in phenotype, were also observed during bacterial growth in broth medium $[16,17,19]$. Different preexisting chromosomal forms in a clonal bacterial population are likely to give this population an adaptive capacity. It is therefore possible that bacterial populations maintain various subpopulations with different genomic structures as a way to cope with different environments during its life cycle.

Additionally, deletion events in TTo1 $\alpha$ and TTo1 $\alpha$ ' lineages are located within the TTo1/I 'flexible' gene pool. Whereas intragenomic recombination in the 'flexible' gene pool have been widely studied using comparative genomics for different bacterial genera, species, and strains [1-4], similar reports for clonal variants are rare. Gene repertoires of the 'flexible' gene pool may evolve through variations in bacterial subpopulations and then become fixed after bacterial speciation. Such pre-existing or currently existing genomic variations have an important role in evolutionary patterns of natural eukaryotic populations [75]. They may also have a determinant role in bacterial evolution.

\section{Conclusion}

The study of molecular mechanisms underlying genomic plasticity in clonal populations is challenging because classical molecular tools only detect the major genomic state of the population. Such studies are easier in bacterial species with a high rate of bacterial variants. With our model, $P$. luminescens, we identified two new genomic rearrangements, allowing a new research axis for gaining a comprehensive knowledge of bacterial chromosome plasticity. The cryptic consequences of large genomic rearrangements in our model also allow prospective comprehensive analysis of bacterial genome evolution. Therefore, we propose that the $P$. luminescens TTo1 strain represents a new bacterial model for study of genomic plasticity. 


\section{Materials and methods}

Strains, plasmids, primers, and culture media

All bacterial strains and plasmids used in this study are listed in Additional data file 6. Primers are listed in Additional data file 7. P. luminescens was grown at $28^{\circ} \mathrm{C}$ in $\mathrm{LB}$ broth or on nutrient agar $1.5 \%$ (BD Difco ${ }^{\mathrm{TM}}$, Franklin Lakes, New Jersey, USA) for 48 hours. Escherichia coli was grown at $37^{\circ} \mathrm{C}$ in LB broth or on LB supplemented with $1.5 \%$ agar (BD Difco ${ }^{\mathrm{TM}}$, Franklin Lakes, New Jersey, USA). Strains were stored at $80^{\circ} \mathrm{C}$ in LB broth containing $16 \%$ glycerol (vol/vol). Secondary variants were obtained by prolonged culture of primary variants at $28^{\circ} \mathrm{C}$ for 10 days in Schneider's insect medium (Cambrex Bio Science, Walkersville, Maryland, USA) with shaking (TTO1/II [30]), for 10 days in LB broth with shaking $\left(\right.$ TTO1 $\alpha_{/ \mathrm{II}}$ ), or for 3 months in LB broth without shaking

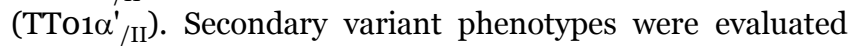
from culture on NBTA (nutrient agar 1,5\%, $25 \mathrm{mg} / \mathrm{l}$ bromothymol blue and $40 \mathrm{mg} / \mathrm{l}$ triphenyl-2,3,5-tetrazolium chloride) plates and on TreGNO plates (see below) at $28^{\circ} \mathrm{C}$. Secondary variants were identified by performing phenotypic tests as previously described [76] and controlled by PCR-restriction fragment length polymorphism of the 16S rRNA gene [77].

\section{Analysis of phenotypic variants on a new selective medium: TreGNO}

Xenorhabdus and Photorhabdus secondary variants are typically selected on NBTA plates to distinguish red secondary variants colonies from blue primary colonies [76]. Because of the high level of pigmentation of Photorhabdus colonies, the use of color assays does not allow clear distinction between primary and secondary variants for Photorhabdus genus. We found that TTo1 secondary variants were able to undergo trehalose fermentation, whereas primary variants can not. On nutrient agar plates supplemented with trehalose (10 g/l) and bromothymol blue ( $25 \mathrm{mg} / \mathrm{l})$, secondary colonies acidified the bromothymol blue and became yellow at $28^{\circ} \mathrm{C}$ after 48 hours. Primary colonies remained green. Furthermore, secondary colonies were flat and large with irregular borders. This new medium was named TreGNO medium and was routinely used for the discrimination of Photorhabdus luminescens strain TTo1 phenotypic variants.

\section{PFGE and DNA electrophoresis}

Intact genomic DNA was extracted in agarose plugs as follows. Bacterial cells grown on nutrient agar plates were suspended in phosphate-buffered saline (GIBCO ${ }^{\circledR}$ Invitrogen, Carlsbad, California, USA) to a turbidity of 1.25 at $650 \mathrm{~nm}$, included in $1 \%$ (vol/vol) low melting agarose (SeaPlaque ${ }^{\circledR}$ GTG, FMC BioProducts, Rockland, Massachusetts, USA) solution and then subjected to lysis as described previously [78].

NotI and ApaI hydrolysis were performed by incubation of the agarose plugs overnight with 40 units of the endonuclease in buffer recommended by the supplier (New England Biolabs, Hertfordshire, UK), at $37^{\circ} \mathrm{C}$ for NotI and $25^{\circ} \mathrm{C}$ for
ApaI. PFGE was carried out in a contour-clamped homogeneous field electrophoresis apparatus CHEF-DRII (Bio-Rad, Hercule, California, USA) in a $0.8 \%$ agarose gel in $0.5 \times$ Trisborate-EDTA (TBE) at $10^{\circ} \mathrm{C}$. PFGE conditions were as follows: for NotI fragments, a 35 to 5 second pulse ramp for 47 hours followed by a constant pulse time of 50 seconds for 6 hours at $4.5 \mathrm{~V} / \mathrm{cm}$; and for ApaI fragments, 35 to 5 seconds for 35 hours, followed by 5 seconds to 1 second for 4 hours at $4.5 \mathrm{~V} / \mathrm{cm}$.

I-CeuI hydrolysis was performed as described previously [79]. For the separation of I-CeuI fragments, different electrophoresis conditions were selected according to fragment size: a pulse ramp from 5 to 50 seconds for 24 hours at $6 \mathrm{~V} /$ $\mathrm{cm}$ for fragments with size below $700 \mathrm{~kb}$; and a pulse ramp from 150 to 400 seconds for 45 hours at $4.5 \mathrm{~V} / \mathrm{cm}$ for I-CeuI fragments for fragments between $700 \mathrm{~kb}$ and 1 megabase. For I-CeuI fragments larger than 1 megabase, PFGE was performed on Rotaphor apparatus (Biometra, Goettingen, Germany) using $0.7 \%$ agarose gels in $0.5 \times$ TBE buffer. The electrophoresis conditions used were as follows: 50 to $47 \mathrm{~V}$ (linear ramp), 6, ooo to 1,00o seconds decreasing pulses (logarithmic ramp), with a increasing angle from 96 to $105^{\circ}$, buffer temperature $11^{\circ} \mathrm{C}$, for 240 hours. I-CeuI PFGE patterns were compared by calculating the Dice coefficient for each pair [8o]. Patterns were clustered by UPGMA using the Phylip program package [81].

HindIII-hydrolyzed DNA was subjected to electrophoresis for 3 hours at $2.6 \mathrm{~V} / \mathrm{cm}$ in a $0.8 \%$ agarose gel in $0.5 \times$ TBE using SubCell apparatus (Bio-Rad) [13].

\section{Southern blotting, probes, and hybridization experiments}

Electrophoresis gels were transferred onto a Nytran N SuperCharge nylon membrane (Schleicher and Schuell, Dassel, Germany) by vacuum blotting in $20 \times \mathrm{SSC}$ (Euromedex, Souffelweyersheim, France).

A digoxigenin-labeled probe targeting 16S rRNA gene was obtained by PCR from genomic DNA of $P$. luminescens strain $\mathrm{TTO}_{/ \mathrm{I}}$, using primers $27 \mathrm{f}$ and $1492 \mathrm{r}$ with a dNTP mixture containing $0.1 \mathrm{mmol} / \mathrm{l}$ digoxigenin-dUTP [13].

Probes $\mathrm{B}$ and $\mathrm{H}$ were obtained using respectively small fragment insert from plg2711 and large fragment inserts from plbac4go8, plbac6h12, plbac3a1o, plbac3co4, and plbac2f12. Fragment inserts were purified, sonicated into fragments of between 1 and $10 \mathrm{~kb}$ if insert size was higher than $10 \mathrm{~kb}$, and labeled with digoxygenin by random priming (Dig DNA labeling Kit; Roche, Meylan, France). Hybridization of the probes was detected using a CSPD chemiluminescent system (Roche). 


\section{Standard DNA manipulations}

Genomic DNA was extracted as previously described [56] and stored at $4^{\circ} \mathrm{C}$. We PCR-amplified the lopT1 deletion region with Taq polymerase (Invitrogen, Carlsbad, California, USA), in accordance with the manufacturer's recommendations, using the PlopT1.fw an PlopT1.rev primers. The region $\mathrm{H}$ was amplified by PCR with the Herculase Enhanced DNA polymerase (Stratagene, Amsterdam Zuidoost, Pays Bas), in accordance with the manufacturer's recommendations, using the R-3236, F-3249, R-3238bis, and F-3254 primers. For sequencing region $\mathrm{H}$ deletions, we purified the $4.8 \mathrm{~kb}$ and 5.2 $\mathrm{kb}$ fragments using the Montage PCR kit (Millipore, Guyancourt, France) and sequenced using PCR primers and chromosome walking (Millegen, Toulouse, France). Sequencing of the $5.2 \mathrm{~kb}$ fragment central region of the fragment failed probably because of the presence of repetitions. A $3.2 \mathrm{~kb}$ central region was therefore amplified by PCR with PstIdMutF and XbaIdMutR primers. The amplicon was hydrolyzed by $P s t \mathrm{I}$ and $X b a \mathrm{I}$, ligated into PstI- and $X b a \mathrm{I}$-hydrolyzed pUC19, and inserted into E. coli XLiblue by transformation. The resulting plasmid was purified by Nucleobond AX-10o kit (Macherey-Nagel, Hoerd, France), and the insert was sequenced with PstIdMutF and XbaIdMutR primers and then by chromosome walking.

\section{DNA microarray hybridization and analysis}

DNA microarray hybridization and analysis were performed as previously described [56].

\section{Quantitative PCR analysis}

Quantitative PCR was performed in triplicate using the LightCycler FastStart DNA MasterPLUS SYBR Green I kit from Roche Diagnostics with 1 ng genomic DNA and $1 \mu \mathrm{mol} / \mathrm{l}$ specific primers targeting fliC (L-1954 and R-1954), mrfJ (L0778 and R-0778), dnaQ (L-0943 and R-0943), and pilN (L1051 and R-1051). The enzyme was activated for 10 minutes at $95^{\circ} \mathrm{C}$. Reactions were performed in triplicate at $95^{\circ} \mathrm{C}$ for $5 \mathrm{sec}-$ onds, $60^{\circ} \mathrm{C}$ for 5 seconds and $72^{\circ} \mathrm{C}$ for 10 seconds ( 45 cycles), and monitored in the Light Cycler (Roche). Melting curves were analyzed for each reaction; all reactions exhibited a single peak. The amount of PCR product was calculated with standard curves obtained from PCR with serially diluted TTo1/I genomic DNA. All data are presented as ratios, with gyrB (primers L-0004 and R-0004) as a control (95\% confidence limits).

\section{Sequence analysis}

Sequence annotation of the TTo1 $/$ I genome was obtained from the MaGe database [82]. We evaluated amino-acid and nucleotide similarity using BLASTP and BLASTN software [83]. We used Repseek software, previously Nosferatu [46], to detect approximate repeats in large DNA sequences.

\section{Pathogenicity assays}

In vivo infection assays were performed as previously described [45]. We performed three independent experi- ments for each variant. Statistical analysis were performed as previously described [84].

\section{Antibiosis plate assays}

Antibiosis assays were performed as previously described [76] with the following bacterial species: Micrococcus luteus, Staphylococcus epidermidis CIP 6821, Staphylococcus aureus CIP 7625, Escherichia coli CIP 7624, Proteus vulgaris CIP 5860, Pseudomonas aeruginosa CIP 76.110, Corynebacterium xerosis, Ochrobactrum intermedium LMG $3301^{\mathrm{T}}$, Ochrobactrum anthropi ATCC $49188^{\mathrm{T}}$, Ochrobactrum sp. FR49, Erwinia amylovora CFBP1430, Pseudomonas sp. BW11M, Salmonella enterica 14028s, and Yersinia enterocolitica serotype 08 .

\section{Abbreviations}

$\mathrm{CV}$, colonial variant; kb, kilobase; NBTA, nutrient agar supplemented with bromothymol blue and triphenyl-2,3,5-tetrazolium chloride; PCR, polymerase chain reaction; PFGE, pulsed field gel electrophoresis; PV, phenotypic variant; Rhs, recombination hotspot; RPT, repetition units; SCV, smallcolony variant; TBE, Tris-borate-EDTA; TreGNO, nutrient agar with trehalose and bromothymol blue.

\section{Authors' contributions}

SG, SP, and AG characterized bacterial variants. SG, AL, and CL provided molecular materials. SG and AL performed microarray analysis. SG, CT, and EJ-B provided PFGE analysis. SG analyzed sequence data. SG wrote the paper with contributions from $\mathrm{AG}$ and EJ-B.

\section{Additional data files}

The following additional data files are available with this paper. Additional data file 1 is a figure showing the deletion in the lopT1 gene in $\mathrm{TTO}_{/ \mathrm{I}}$ strain and the six variants. Additional data file 2 is a figure showing PFGE of I-CeuIhydrolyzed genomic DNA of TTo1/I strain and the six variants. Additional data file 3 is a figure showing the copy number of $16 \mathrm{~S}$ rDNA in $\mathrm{TTo1}_{/ \mathrm{I}}$ and the six variants. Additional data file 4 is a table listing the TTo1/I missing genes in $\mathrm{TTO}_{\alpha / \mathrm{I}}$ and $\mathrm{VAR}^{*}$ variants according whole-genome comparison using DNA microarray. Additional data file 5 is a table listing the TTo1/I amplified genes in TTo1 $\alpha_{/ \mathrm{I}}$ and $\mathrm{VAR}^{*}$ variants, according to whole-genome comparison using DNA microarray. Additional data file 6 is a table listing strains and plasmids used in this study. Additional data file 7 is a table listing primers used in this study.

\section{Acknowledgements}

This study received financial support from the Institut National de la Recherche Agronomique (grant SPE 2004-II33-2). We thank Sylviane Derzelle for the TTOI /II gift, Eric Duchaud and Lionel Frangeul for help with the circular map of DNA microarray data, Agnès Masnou and Emmanuelle 
d'Alençon for help in PFGE experiments, and Karine Brugirard-Ricaud for IopTI deletion identification. We thank Marie-Christine Guérin and Joël Martin for expert technical assistance with quantitative PCR.

\section{References}

I. Dobrindt $U$, Hacker J: Whole genome plasticity in pathogenic bacteria. Curr Opin Microbiol 200I, 4:550-557.

2. Joyce EA, Chan K, Salama NR, Falkow S: Redefining bacterial populations: a post-genomic reformation. Nat Rev Genet 2002, 3:462-473.

3. Dobrindt $U$, Hochhut $B$, Hentschel $U$, Hacker J: Genomic islands in pathogenic and environmental microorganisms. Nat Rev Microbiol 2004, 2:414-424.

4. Abby S, Daubin V: Comparative genomics and the evolution of prokaryotes. Trends Microbiol 2007, I5:|35-|4I.

5. Hallet B: Playing Dr Jekyll and Mr Hyde: combined mechanisms of phase variation in bacteria. Curr Opin Microbiol 200I, 4:570-58I.

6. Dybvig K: DNA rearrangements and phenotypic switching in prokaryotes. Mol Microbiol 1993, I0:465-471.

7. Woude MW van der, Baumler AJ: Phase and antigenic variation in bacteria. Clin Microbiol Rev 2004, 17:58I-6II.

8. Flores M, Brom S, Stepkowski T, Girard ML, Davila G, Romero D, Palacios R: Gene amplification in Rhizobium: identification and in vivo cloning of discrete amplifiable DNA regions (amplicons) from Rhizobium leguminosarum biovar phaseoli. Proc Natl Acad Sci USA 1993, 90:4932-4936.

9. Riehle MM, Bennett AF, Long $A D$ : Genetic architecture of thermal adaptation in Escherichia coli. Proc Natl Acad Sci USA 200I, 98:525-530.

10. Edwards K, Linetsky I, Hueser C, Eisenstark A: Genetic variability among archival cultures of Salmonella typhimurium. FEMS Microbiol Lett 200I, 199:215-219.

II. Liu GR, Edwards K, Eisenstark A, Fu YM, Liu WQ, Sanderson KE, Johnston RN, Liu SL: Genomic diversification among archival strains of Salmonella enterica serovar Typhimurium LT7. J Bacteriol 2003, I85:2|3|-2|42.

12. Porwollik S, Wong RM, Helm RA, Edwards KK, Calcutt M, Eisenstark $A, M c C l e l l a n d ~ M:$ DNA amplification and rearrangements in archival Salmonella enterica serovar Typhimurium LT2 cultures. J Bacteriol 2004, 186:1678-1682.

13. Teyssier C, Marchandin H, Siméon de Buochberg M, Ramuz M, JumasBilak E: Atypical 16S rRNA gene copies in Ochrobactrum intermedium strains reveal a large genomic rearrangement by recombination between rrn copies. I Bacteriol 2003, I 85:290I-2909.

14. Flores M, Mavingui P, Perret X, Broughton WJ, Romero D, Hernandez G, Davila G, Palacios R: Prediction, identification, and artificial selection of DNA rearrangements in Rhizobium: toward a natural genomic design. Proc Natl Acad Sci USA 2000, 97:9|38-9|43

15. Mavingui P, Flores M, Guo X, Davila G, Perret X, Broughton WJ, Palacios R: Dynamics of genome architecture in Rhizobium sp. strain NGR234. | Bacteriol 2002, 184: |7|- I76.

16. Guo X, Flores M, Mavingui P, Fuentes SI, Hernandez G, Davila G, Palacios R: Natural genomic design in Sinorhizobium meliloti: novel genomic architectures. Genome Res 2003, 13:1810-1817.

17. Stover CK, Pham XQ, Erwin AL, Mizoguchi SD, Warrener P, Hickey MJ, Brinkman FS, Hufnagle WO, Kowalik DJ, Lagrou M, Garber RL, Goltry L, Tolentino E, Westbrock-Wadman S, Yuan Y, Brody LL, Coulter SN, Folger KR, Kas A, Larbig K, Lim R, Smith K, Spencer D, Wong GK, Wu Z, Paulsen IT, Reizer J, Saier MH, Hancock RE, Lory $\mathrm{S}$, et al.: Complete genome sequence of Pseudomonas aeruginosa PAOI, an opportunistic pathogen. Nature 2000, 406:959-964.

18. Helm RA, Lee AG, Christman HD, Maloy S: Genomic rearrangements at rrn operons in Salmonella. Genetics 2003, 165:951-959.

19. Parkhill J, Wren BW, Thomson NR, Titball RW, Holden MT, Prentice MB, Sebaihia M, James KD, Churcher C, Mungall KL, Baker S, Basham $D$, Bentley SD, Brooks K, Cerdeño-Tárraga AM, Chillingworth T, Cronin A, Davies RM, Davis P, Dougan G, Feltwell T, Hamlin N, Holroyd S, Jagels K, Karlyshev AV, Leather S, Moule S, Oyston PC, Quail $M$, Rutherford K, et al.: Genome sequence of Yersinia pestis, the causative agent of plague. Nature 200I, 413:523-527.

20. Volff JN, Altenbuchner J: Genetic instability of the Streptomyces chromosome. Mol Microbiol 1998, 27:239-246.

21. Boemare NE: Biology, taxonomy and systematics of Photorhabdus and Xenorhabdus. In Entomopathogenic Nematology Edited by: Gaugler R. Wallingford, UK: CABI Publishing; 2002:35-56.

22. Forst S, Dowds B, Boemare N, Stackebrandt E: Xenorhabdus and Photorhabdus spp.: bugs that kill bugs. Annu Rev Microbiol I997, $5 \mathrm{I}: 47-72$.

23. ffrench-Constant $R$, Waterfield N, Daborn P, Joyce $S$, Bennett $H, A u$ C, Dowling A, Boundy S, Reynolds S, Clarke D: Photorhabdus: towards a functional genomic analysis of a symbiont and pathogen. FEMS Microbiol Rev 2003, 26:433-456.

24. Joyce SA, Watson RJ, Clarke DJ: The regulation of pathogenicity and mutualism in Photorhabdus. Curr Opin Microbiol 2006, 9:127-132.

25. Akhurst RJ: Morphological and functional dimorphism in Xenorhabdus spp., bacteria symbiotically associated with the insect pathogenic nematodes Neoaplectana and Heterorhabditis. J Gen Microbiol 1980, I 2 1:303-309.

26. Boemare NE, Akhurst RJ: Biochemical and physiological characterization of colony form variants in Xenorhabdus spp. (Enterobacteriaceae). J Gen Microbiol 1988, I34:75I-76I.

27. Forst S, Clarke D: Bacteria-nematode symbiosis. In Entomopathogenic Nematology Edited by: Gaugler R. Oxon, UK: CAB International; 2002:57-77.

28. Joyce SA, Clarke DJ: A hexA homologue from Photorhabdus regulates pathogenicity, symbiosis and phenotypic variation. Mol Microbiol 2003, 47: 1445- 1457.

29. O'Neill KH, Roche DM, Clarke DJ, Dowds BC: The ner gene of Photorhabdus: effects on primary-form-specific phenotypes and outer membrane protein composition. J Bacteriol 2002, 184:3096-3105.

30. Derzelle S, Ngo S, Turlin E, Duchaud E, Namane A, Kunst F, Danchin A, Bertin P, Charles JF: AstR-AstS, a new two-component signal transduction system, mediates swarming, adaptation to stationary phase and phenotypic variation in Photorhabdus luminescens. Microbiology 2004, I 50:897-910.

31. Turlin E, Pascal G, Rousselle JC, Lenormand P, Ngo S, Danchin A, Derzelle S: Proteome analysis of the phenotypic variation process in Photorhabdus luminescens. Proteomics 2006, 6:2705-2725

32. Hu K, Webster JM: In vitro and In vivo characterization of a small-colony variant of the primary form of Photorhabdus luminescens MD (Enterobacteriaceae). Appl Environ Microbiol 1998, 64:3214-3219.

33. Gerritsen LJ, de Raay G, Smits PH: Characterization of form variants of Xenorhabdus luminescens. Appl Environ Microbiol 1992, 58:1975-1979.

34. Hurlbert RE, Xu J, Small CL: Colonial and cellular polymorphism in Xenorhabdus luminescens. Appl Environ Microbiol 1989, 55: II36-II43.

35. Wouts WM: The primary form of Xenorhabdus species (Enterobacteriaceae, Eubacteriales) may consist of more than one bacterial species. Nematologica 1990, 36:313-318.

36. Wang $Y$, Bilgrami AL, Shapiro-llan D, Gaugler R: Stability of entomopathogenic bacteria, Xenorhabdus nematophila and Photorhabdus luminescens, during in vitro culture. J Ind Microbiol Biotechnol 2007, 34:73-8I.

37. Proctor RA, von Eiff $C$, Kahl BC, Becker K, McNamara P, Herrmann $M$, Peters G: Small colony variants: a pathogenic form of bacteria that facilitates persistent and recurrent infections. Nat Rev Microbiol 2006, 4:295-305.

38. Wang $\mathrm{H}$, Dowds BC: Phase variation in Xenorhabdus luminescens: cloning and sequencing of the lipase gene and analysis of its expression in primary and secondary phases of the bacterium. J Bacteriol 1993, I75:1665-1673.

39. Frackman $\mathrm{S}$, Anhalt $\mathrm{M}$, Nealson $\mathrm{KH}$ : Cloning, organization, and expression of the bioluminescence genes of Xenorhabdus luminescens. J Bacteriol 1990, 172:5767-5773.

40. Smigielski AJ, Akhurst RJ: Megaplasmids in Xenorhabdus and Photorhabdus spp., bacterial symbionts of entomopathogenic nematodes (families Steinernema and Heterorhabditiae). J Invertebrate Pathol 1994, 64:214-220.

4I. Roche DM, Dowds BC: Identification and sequence of an unstable DNA element in the entomopathogenic bacteria Photorhabdus temperata strain KI22. Lett Appl Microbiol 2002, 35:131-135.

42. Duchaud E, Rusniok C, Frangeul L, Buchrieser C, Givaudan A, Taourit S, Bocs S, Boursaux-Eude C, Chandler M, Charles JF, Dassa E, Derose 
R, Derzelle S, Freyssinet G, Gaudriault S, Médigue C, Lanois A, Powell K, Siguier P, Vincent R, Wingate V, Zouine M, Glaser P, Boemare N, Danchin A, Kunst $F$ : The genome sequence of the entomopathogenic bacterium Photorhabdus luminescens. Nat Biotechnol 2003, $21: 1307-1313$

43. Fischer-Le Saux M, Mauleon H, Constant P, Brunel B, Boemare N: PCR-ribotyping of Xenorhabdus and Photorhabdus isolates from the Caribbean region in relation to the taxonomy and geographic distribution of their nematode hosts. Appl Environ Microbiol 1998, 64:4246-4254.

44. Woodring JL, Kaya HK: Steinernematid and Heterorhabditid nematodes: A Hand Book of Biology and Techniques. In Southern Cooperative Series Bulletin 33I Arkansas Agricultural Experiment Station, Fayetteville, AR: Nematode Subcommittee of the Southern Regional Project S-I35:Entomopathogens for Use in PestManagement Systems; 1988.

45. Brugirard-Ricaud K, Duchaud E, Givaudan A, Girard PA, Kunst F, Boemare N, Brehelin M, Zumbihl R: Site-specific antiphagocytic function of the Photorhabdus luminescens type III secretion system during insect colonization. Cell Microbiol 2005, 7:363-37I.

46. Achaz G, Boyer F, Rocha E, Viari A, Coissac E: Repseek, a tool to retrieve approximate repeats from large DNA sequences. Bionformatics 2007, 23:|19-121.

47. Roth J, Benson N, Galitski T, Haack K, Lawrence J, Miesel L: Rearrangement of the bacterial chromosome: formation and applications. In Escherichia coli and Salmonella: Cellular and Molecular Biology Volume 2. 2nd edition. Edited by: Neidhardt F. Washington, DC: ASM Press; 1996:2256-2276.

48. Hughes D: Evaluating genome dynamics: the constraints on rearrangements within bacterial genomes. Genome Biol 2000, I:REVIEWS0006.

49. Rocha EPC: Order and disorder in bacterial genomes. Curr Opinion Microbiol 2004, 7:519-527.

50. Mira A, Pushker R: Genome architecture and evolution of bacterial pathogens. In Evolutionary Biology of Bacterial and Fungal Pathogens Edited by: Baquero FCN, Cassell GH, Gutiérez JA. Washington, DC: ASM Press; 2008:1 I 15-127.

51. Hill CW: Large genomic sequence repetitions in bacteria: lessons from rRNA operons and Rhs elements. Res Microbiol 1999, 150:665-674.

52. Anderson P, Roth J: Spontaneous tandem genetic duplications in Salmonella typhimurium arise by unequal recombination between rRNA (rrn) cistrons. Proc Natl Acad Sci USA I98I, 78:3।|3-3\|1

53. Wang YD, Zhao S, Hill CW: Rhs elements comprise three subfamilies which diverged prior to acquisition by Escherichia coli. J Bacteriol 1998, I 80:4 |02-4II0.

54. Lin R-J, Capage M, Hill C: A repetitive DNA sequence, Rhs, responsible for duplications within the Escherichia coli K-I 2 chromosome. J Mol Biol 1984, I77: I-18.

55. ffrench-Constant RH, Waterfield N, Burland V, Perna NT, Daborn PJ, Bowen D, Blattner FR: A genomic sample sequence of the entomopathogenic bacterium Photorhabdus luminescens WI4: potential implications for virulence. Appl Environ Microbiol 2000, 66:3310-3329.

56. Gaudriault S, Duchaud E, Lanois A, Canoy AS, Bourot S, Derose R, Kunst F, Boemare N, Givaudan A: Whole-genome comparison between Photorhabdus strains to identify genomic regions involved in the specificity of nematode interaction. J Bacteriol 2006, I88:809-8|4.

57. Romero D, Palacios R: Gene amplification and genomic plasticity in prokaryotes. Annu Rev Genet 1997, 31 :91-III.

58. Craven SH, Neidle EL: Double trouble: medical implications of genetic duplication and amplification in bacteria. Future Microbiol 2007, 2:309-32I.

59. Reams $A B$, Neidle EL: Gene amplification involves site-specific short homology-independent illegitimate recombination in Acinetobacter sp. strain ADPI. J Mol Biol 2004, 338:643-656.

60. Yanai K, Murakami T, Bibb M: Amplification of the entire kanamycin biosynthetic gene cluster during empirical strain improvement of Streptomyces kanamyceticus. Proc Natl Acad Sci USA 2006, 103:966I-9666.

61. Fukasawa T, Hirai K, Segawa T, Obonai K: Regional replication of the bacterial chromosome induced by derepression of prophage lambda. IV. Escape synthesis of gal operon in phage 82. Mol Gen Genet 1978, 167:83-93.

62. Imae Y, Fukasawa T: Regional replication of the bacterial chro- mosome induced by derepression of prophage lambda. J Mol Biol 1970, 54:585-597.

63. Osterhout RE, Figueroa IA, Keasling JD, Arkin AP: Global analysis of host response to induction of a latent bacteriophage. $B M C$ Microbiol 2007, 7:82.

64. Frye JG, Porwollik S, Blackmer F, Cheng P, McClelland M: Host gene expression changes and DNA amplification during temperate phage induction. J Bacteriol 2005, 187: I 485-1492.

65. Lindroos H, Vinnere O, Mira A, Repsilber D, Naslund K, Andersson SG: Genome rearrangements, deletions, and amplifications in the natural population of Bartonella henselae. I Bacteriol 2006, 188:7426-7439.

66. Baghdiguian S, Boyer-Giglio M-H, Thaler JO, Bonnot G, Boemare N: Bacteriocinogenesis in cells of Xenorhabdus nematophilus and Photorhabdus luminescens: Enterobacteriaceae associated with entomopathogenic nematodes. Biol Cell I993, 79: 177-185.

67. Galamba A, Soetaert K, Wang XM, De Bruyn J, Jacobs P, Content J: Disruption of adhC reveals a large duplication in the Mycobacterium smegmatis mc(2)155 genome. Microbiology 200I, I 47:328I-3294.

68. Mathee K, Narasimhan G, Valdes C, Qiu X, Matewish JM, Koehrsen M, Rokas A, Yandava CN, Engels R, Zeng E, Olavarietta R, Doud M, Smith RS, Montgomery P, White JR, Godfrey PA, Kodira C, Birren B, Galagan JE, Lory S: Dynamics of Pseudomonas aeruginosa genome evolution. Proc Natl Acad Sci USA 2008, 105:3100-3105.

69. Rocha EP: The replication-related organization of bacterial genomes. Microbiology 2004, 150:1609-1627.

70. Rocha EP, Danchin A: Essentiality, not expressiveness, drives gene-strand bias in bacteria. Nat Genet 2003, 34:377-378.

7I. Bailly-Bechet M, Danchin A, Iqbal M, Marsili M, Vergassola M: Codon usage domains over bacterial chromosomes. PLoS Comput Biol 2006, 2:e37.

72. Esnault E, Valens M, Espeli O, Boccard F: Chromosome structuring limits genome plasticity in Escherichia coli. PLOS Genet 2007, 3:e226.

73. Gaudriault S, Thaler JO, Duchaud E, Kunst F, Boemare N, Givaudan A: Identification of a P2-related prophage remnant locus of Photorhabdus luminescens encoding an R-type phage tail-like particle. FEMS Microbiol Lett 2004, 233:223-23I.

74. Meslet-Cladiere LM, Pimenta A, Duchaud E, Holland IB, Blight MA: In vivo expression of the mannose-resistant fimbriae of Photorhabdus temperata $\mathrm{K} 122$ during insect infection. J Bacteriol 2004, I 86:61| I-622.

75. Barrett RD, Schluter D: Adaptation from standing genetic variation. Trends Ecol Evol 2008, 23:38-44.

76. Boemare N, Thaler J-O, Lanois A: Simple bacteriological tests for phenotypic characterization of Xenorhabdus and Photorhabdus phase variants. Symbiosis 1997, 22:167-175.

77. Brunel B, Givaudan A, Lanois A, Akhurst RJ, Boemare N: Fast and accurate identification of Xenorhabdus and Photorhabdus species by restriction analysis of PCR-amplified I6S rRNA genes. Appl Environ Microbiol 1997, 63:574-580.

78. Jumas-Bilak E, Michaux-Charachon S, Bourg G, O'Callaghan D, Ramuz $M$ : Differences in chromosome number and genome rearrangements in the genus Brucella. Mol Microbiol 1998, 27:99-106.

79. Teyssier C, Marchandin H, Masnou A, Jeannot J-L, Siméon de Buochberg $M$, Jumas-Bilak E: Pulsed-field gel electrophoresis to study the diversity of whole-genome organization in the genus Ochrobactrum. Electrophoresis 2005, 26:2898-2907.

80. Grothues D, Tummler B: New approaches in genome analysis by pulsed-field gel electrophoresis: application to the analysis of Pseudomonas species. Mol Microbiol 199I, 5:2763-2776.

8I. Felsenstein J: PHYLIP (Phylogeny Inference Package, Version 3.6 Seattle, WA: Department of Genome Sciences, University of Washington, Seattle, WA; 2004

82. MaGe [http://www.genoscope.cns.fr/agc/mage/wwwpkgdb/Mage Home/index.php?webpage $=$ mage]

83. Altschul SF, Madden TL, Schaffer AA, Zhang J, Zhang Z, Miller W, Lipman DJ: Gapped BLAST and PSI-BLAST: a new generation of protein database search programs. Nucleic Acids Res 1997, 25:3389-3402.

84. Brillard J, Duchaud E, Boemare N, Kunst F, Givaudan A: The PhIA hemolysin from the entomopathogenic bacterium Photorhabdus luminescens belongs to the two-partner secretion family of hemolysins. J Bacteriol 2002, 184:387I-3878. 